\title{
CATATAN SINGKAT MENGENAI \\ KOMPLEKS MAKAM BANYUSUMURUP, IMOGIRI
}

\author{
Oleh : Novida Abbas
}

Perwujudan seni bangun yang bercorak Islam di Indonesia dapat dilihat dalam bentuk masjid, bangunan makam, dan istana atau kraton. Hasil seni bangun bercorak Islam yang muncul pertama kali di Indonesia adalah bangunan makam, seperti yang dapat dilihat antara lain di Samudra Pasai dan Leran (Moquette, 1912 : 536 - 548). Dalam bidang studi arkeologi Islam telah diteliti sejumlah besar bangunan makam beserta berbagai aspeknya, antara lain aspek seni bangun, seni hias, dan pola tata letak. Banyak hal yang dapat diungkapkan dari studi mengenai makam, misalnya variasi bentuk dan hiasan pada nisan serta jirat, seni bangun dan seni hias makam yang berkembang di suatu tempat pada suatu kurun masa tertentu, persebaran pengaruh budaya antardaerah, dan lain-lain.

Di Jawa, bangunan makam yang merupakan salah satu hasil seni bangun bercorak Islam, tersebar diberbagai tempat. Makam-makam yang berasal dari masa awal penyebaran Islam di Jawa sebagian besar terdapat di daerah pesisir utara Jawa, yaitu terutama merupakan makam para penyebar agama Islam di Jawa pada masa itu. Sebagai contoh misalnya makam Sunan Giri di Giri (Gresik), Sunan Drajat di Drajat (Lamongan), Sunan Bonang di Tuban, Sunan Kudus di Kudus,dan Sunan Gunung Jati di Cirebon. Dari masa yang lebih kemudian, ketika Islam telah berhasil menyebar ke berbagai lapisan masyarakat, yaitu ketika mulai timbul kerajaan-kerajaan bercorak Islam, dapat dilihat tinggalan berupa bangunanbangunan makam para raja beserta kaum kerabatnya. Bangunan makam raja-raja dengan kaum kerabatnya dapat dijumpai baik di daerah pesisir maupun pedalaman. Di daerah pesisir misalnya terdapat kompleks makam Raden Patah beserta kerabatnya di Demak, kompleks makam Sunan Mangkurat I di Tegal, dan kompleks makam Maulana Yusuf dengan keturunannya di Banten. Sedangkan di pedalaman dijumpai jkompleks makam raja-raja Mataram Islam di Kota Gede dan Imógiri, Yogyakarta. Dari masa-masa selanjut nya terdapat pula makam-makam tokoh lokal yang masih dikeramatkan, misalnya makam Kyai Jogonegoro di daerah Selomerto. Wonosobo, yang dianggap sebagai penyebar agama Islam di daerah tersebut (Lucas P. Koestoro, 1984 : 12) dan makam Menak Koncar di dacrah Biting. Lumajang, yang dianggap sebagai salah seorang cikal bakal daerah Lumajang.

Dalam tulisan ini akan dibicarakan mengenai sebuah kompleks makam vang terdapat di Banyusumurup, Imogiri. Daerah Imogiri dikenal sebagai tcmpal pemakiman raja-raja Mataram Islam dengan kaum kerabatnya 
sejak Sultan Agung. Di daerah Imogiri terdapat tiga kompleks makam, yang seluruhnya merupakan kompleks makam para raja Mataram Islam maupun kaum kerabatnya. Ketiga kompleks makam tersebut adalah kompleks makam Giriloyo kompleks makam Imogiri (Pajimatan), dan kompleks makam Banyusumurup. Di antara ketiga kompleks makam tersebut yang tertua adalah kompleks makam Giriloyo. Menurut cerita setempat. sebenarnya Giriloyo direncanakan akan digunakan sebagai tempat pemakaman Sultan Agung. Akan tetapi karena paman Sultan Agung, yaitu Panembahan Juminah, lebih dulu meninggal, maka yang dimakamkan di Giriloyo adalah Panembahan Juminah. Sedangkah Sultan Agung kemudian memilih lokasi lain sebagai tempat pemakamannya, yang terletak tidak jauh dari Giriloyo, yaitu Imogiri (Inajati Adrisijanti, 1973 : lampiran II). Sedangkan kompleks makam yang termuda di antara ketiga kompleks makam tersebut di atas adalah Banyusumurup. Banyusumurup merupakan tempat pemakaman salah seorang kerabat Sultan Agung, yaitu Pangeran Pekik, yang dianggap sebagai pembangkang terhadap kekuasaan raja yang memerintah pada masa itu, yaitu Sunan Mangkurat I.

Kompleks makam Banyusumurup terletak di wilayah kelurahan Girirejo, kecamatan Imogiri, kabupaten Bantul, D.I. Yogyakarta. Kompleks makam tersebut terletak sekitar $2 \mathrm{~km}$ di sebelah selatan kompleks makam Imogiri, yaitu pada sebuah lembah yang dikelilingi oleh tiga gunung. Di sebelah utara terdapat gunung Mengger, di sebelah timur gunung Tubalung. dan sebelah selatan terdapat gunung Sendanglegi.

Tokoh utama yang dimakamkan di Banyusumurup.adalah Pangeran Pekik. Selain itu terdapat makam-makam Pangeran Lamongan. Rara Oyi, dan 49 makam lain yang kemungkinan merupakan makam-makam para kerabat dan pengikut Pangeran Pekik (Lampiran 1). Pangeran Pekik adalah putra Pangeran Surabaya, yaitu penguasa Surabaya pada sekitar awal abad 17 Masehi. Setelah Surabaya ditaklukkan oleh Mataram pada tahun 1625 Masehi (Graaf, 1941 : 2), maka Pangeran Pekik diperintahkan untuk pindah ke Mataram oleh Sultan Agung. Setelah pindah ke Mataram. Pangeran Pekik kemudian kawin dengan adik Sultan Agung, yaitu Ratu Pandan Sari (Olthoff, 1941 : 134). Selanjutnya salah seorang putri Pangeran Peluk kawin dengan putra Sultan Agung, yaitu Pangeran Adipati Mataram, yang nantinya bergelar Sunan Mangkurat I. Dari hubungan kedua perkawinan tersebut, maka Pangeran Pekik menjadi ipar Sultan Agung dan sekaligus mertua Sunan Mangkurat I. Dan bidang kebudayaan. Pangeran Pckik dikenal pula sebagai pencipta salah satu bentuk wayang yang dibuat dari kulit kerbau. Jenis wayang ini mengisahkan riwayat Damar Wulan dan disebut wayang krucil (Serrurier, 1896 : 57). Selain itu ia clikcnal pula sebagai penggubah suluk Damar Wulan (Graaf, 1941 : 34). 
Dari beberapa sumber diketahui bahwa Pangeran Pekik dibunuh atas perintah Sunan Mangkurat I. Babad Tanah Jawi menyebutkan bahwa Pangeran Pekik dibunuh bersama putra-putra dan 40 orang pengikutnya (Olthoff, 1941 : 153 : 154). Dari sumber Belanda antara lain disebutkan bahwa Pangeran Pekik dibunuh pada tanggal 21 Februari 1659 bersama dua saudara, seorang putra, dua kemenakan dan 60 panglimanya (Graaf, 1962 : 5). Mengenai sebab-sebab dibunuhnya Pangeran Pekik diceritakan sebagai berikut : pada suatu ketika Pangeran Pekik membawa Rara Oyi untuk diberikan kepada cucunya, yaitu Mangkurat II. Rara Oyi tersebut sebenarnya akan diperistri oleh Mangkurat I. Setelah mengetahui hal itu, Mangkurat I menuduh Pangeran Pekik berniat untuk memberontak terhadap kekuasaan Mataram dan memerintahkan agar Pangeran Pekik beserta kaum kerabat dan pengikutnya dibunuh. Sedangkan Rara Oyi akhirnya dibunuh oleh Mangkurat II atas perintah Mangkurat I. Selain itu, muncul pula pendapat lain yang mengatakan bahwa Pangeran Pekik sebenarnya mempunyai niat untuk memberontak terhadap Mataram dengan berusaha bekerja sama dengan Belanda (Graaf, 1941 : 36). Setelah Mangkurat I mengetahui hal ini, maka ia memerintahkan agar Pangeran Pekik dengan kerabat dan pengikutnya dibunuh. Pangeran Pekik beserta kaum kerabat dan para pengikutnya kemudian dimakamkan di Banyusumurup.

\section{III}

Kompleks makam Banyusumurup terdiri atas dua halaman yang masing-masing dikelilingi tembok bata dan berdenah empat persegi panjang (Gambar : 1). Halaman pertama disebut bale panyerenan, yaitu sebagai tempat untuk meletakkan jenazah sebelum dimakamkan di halaman kedua. Halaman pertama ini sekarang digunakan sebagai tempat menunggu bagi para peziarah dengan sebuah bangsal pada sisi utara. Sedangkan makammakam yang terdapat di kompleks ini terletak di halaman kedua. Menurut keterangan juru kunci makam, di halaman kedua sisi utara dulunya terdapat scbuah cungkub. Saat ini yang tersisa hanyalah umpak-umpak batu bekas tempat meletakkan tiang-tiang cungkup tersebut. Umpak-umpak batu itu seluruhnya berjumlah 14 buah dengan dua macam ukuran. Pada umpak-umpak itu terdapat hiasan bermotif daun teratai dalam bentuk hati. Motif semacam ini terdapat pula pada umpak-umpak batu dari Majapahil (Uka Tjandrasasmita, 1975:94) dan pada bagian dasar cungkub makam Sunan Bonang di Tuban.

Pada halaman kedua sisi utara, yaitu di tempat yang dulunya dinaungi cungkub. lerdapat 21 buah makam. Dua di antaranya terletak paling utara, Yiitu morupakan makam Pangeran Pekik dan Pangeran Lamongan. Sedangkan makam lainnya antara lain adalah makam Rara Oyi dan Putra Timur. yaitı putra Pangeran Pekik yang terbunuh ketika masih kecil. Selain 21 makam tersebut di atas, terdapat pula 31 makam lainnya yang dikiltakin sebagai para kerabat maupun pengikut Pangeran Pekik. 


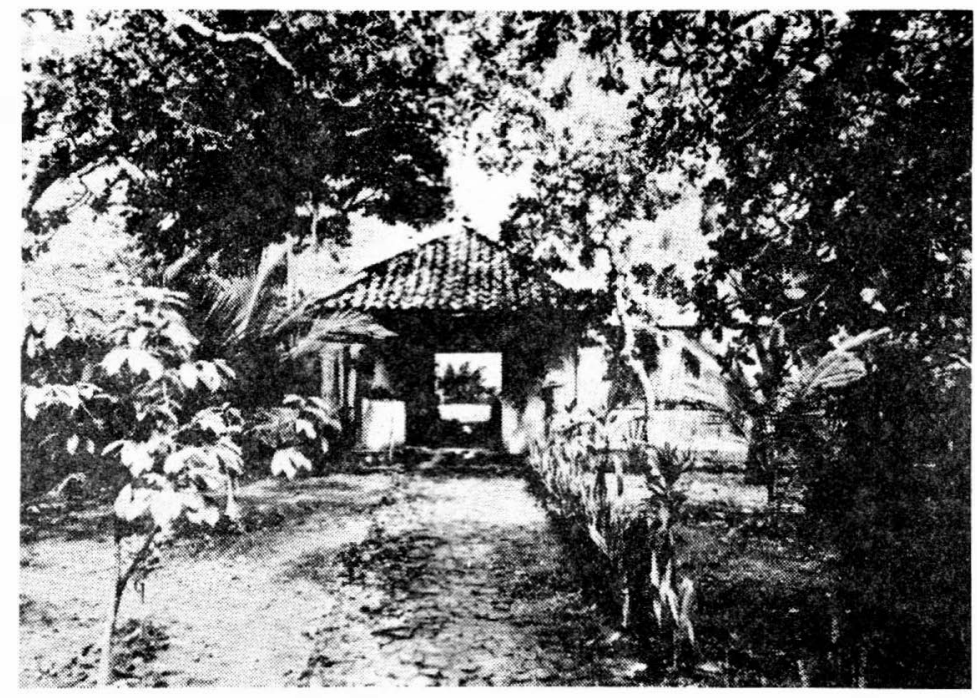

Halaman pertąma kompleks makam Banyusumurup.

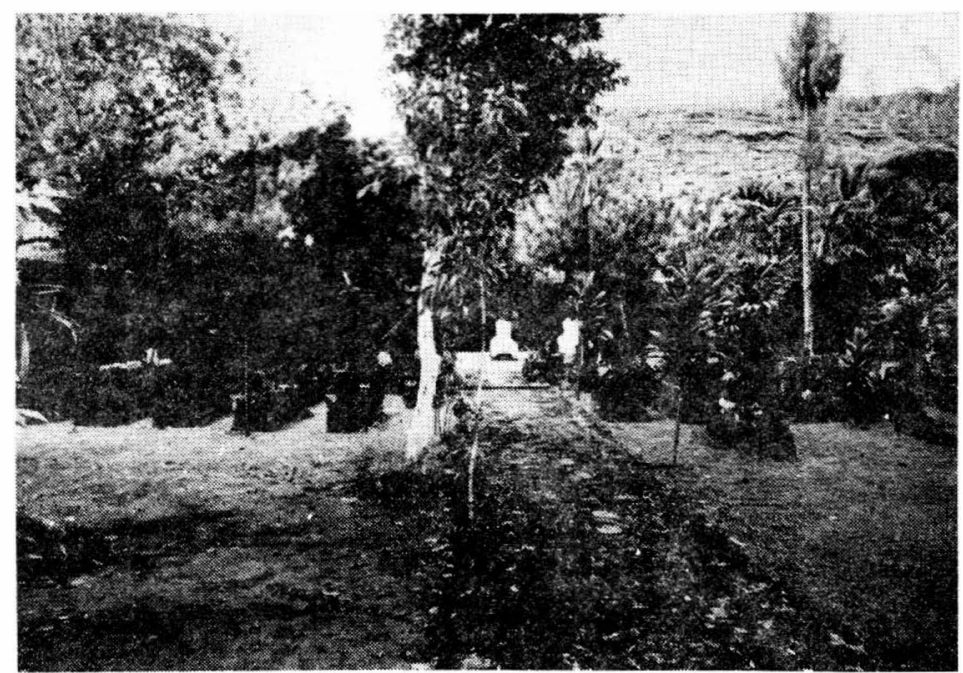

Halaman kedua kompleks makam Banyusumurup. 
dapat pula 31 makam lainnya yang dikatakan sebagai para kerabat maupun pengikut Pangeran Pekik.

Makam-makam tersebut di atas sebagian besar dibuat dari batu andesit kecuali makam Pangeran Pekik dan Pangeran Lamongan yang dibuat dari batu kapur. Khusus makam Pangeran Pekik, jirat dan nisannya merupakan kesatuan yang dibuat dari satu batu. Jirat makam-makam tersebut dapat dibedakan dalam tiga kelompok, yaitu jirat yang disusun dari balok-balok batu secara horizontal, jirat bertingkat, dan jirat yang terdiri dari satu balok batu. Sedangkan nisan-nisannya memiliki bentuk dasar yang sama, yaitu berbentuk kurawal, dengan beberapa macam variasi. Sebagian besar nisan-nisan tersebut polos, dan beberapa di antaranya mempunyai hiasan dengan motif tumpal, pinggir awan, bintang, dan bulan sabit. Dua diantara makam-makam yang terdapat di halaman kedua sisi utara, yaitu makam 4 dan makam 6, mempunyai tulisan dalam huruf Jawa tengahan pada nisan-nisannya. 1

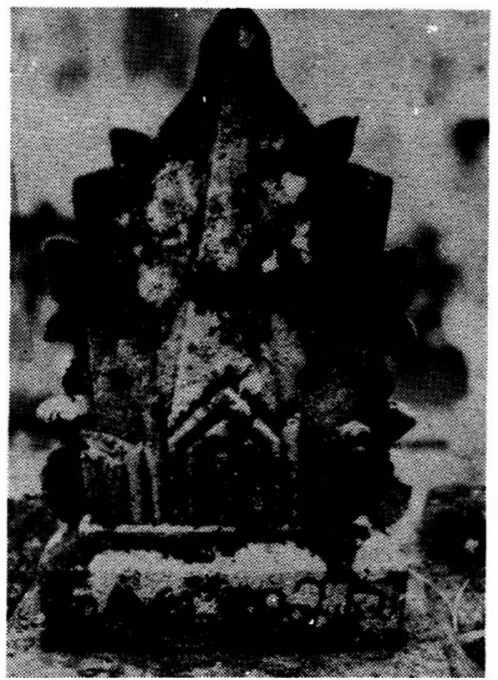

Tulisan pada nisan kaki makam 4.

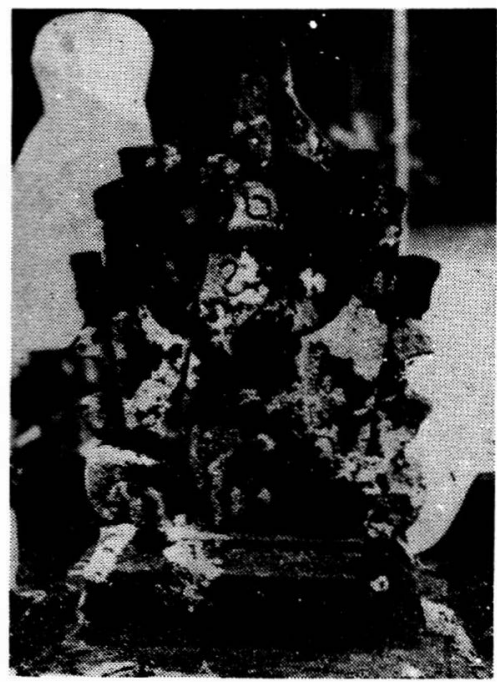

Tulisan pada nisan kepala makam 6. 
Pada makam 4 tulisan tersebut terdapat pada bagian bawah nisan kaki sisi dalam, yaitu :
257
$(37)$
2)
$\int$
$\eta$
$\mathrm{Ca}$
kra
na
ga
ra

Padà makam 6, tulisan terdapat pada bagian badan nisan kepala sisi luar dan dalam, serta pada bagian badan nisan kaki sisi luar dan dalam. 3 Tulisan pada bagian badan nisan kepala sisi luar adalah :

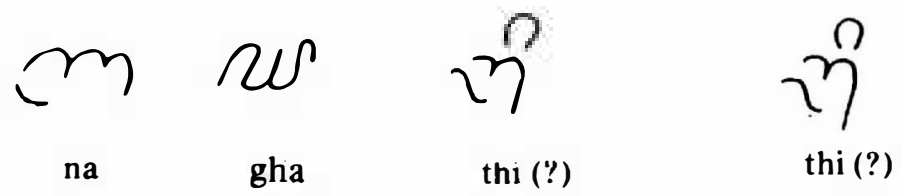

Nisan kepala sisi dalam :

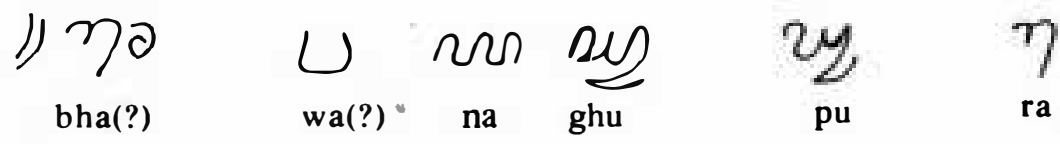

Pada nisan kaki sisi luar terdapat tulisan :

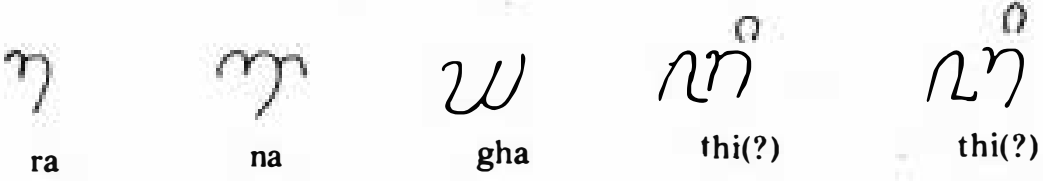

Sedangkan pada nisan kaki sisi dalam adalah

1) 2

hha

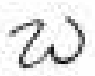

wai

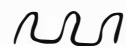

na

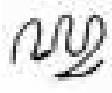

gu 
Di kompleks makam ini setiap hari Senin dan Jum'at dilakukan upacara caces dahnr, yaitu semacam upacara ziarah yang dilakukan oleh juru kunci makam dari kraton Surakarta maupun Yogyakarta. Dalam upacara caos dahar tersebut tidak ada kerabat kerajaan dari kraton Surakarta maupun Yogyakarta yang hadir. Uba rampe untuk keperluan tersebut hanya dikirim dari kraton Surakarta dan Yogyakarta, sedangkan pelaksanaan caos dahar diserahkan sepenuhnya kepada para juru kunci makam.

\section{IV}

Hasil pengamatan terhadap kompleks makam Banyusumurup menunjukkan adanya beberapa perbedaan dengan hal-hal yang lazim dijumpai dalam sebuah kompleks makam, dalam hal ini yang dimaksud adalah kompleks makam tokoh penting dalam masanya, baik tokoh kenegaraan maupun tokoh keagamaan. Perbedaan tersebut antara lain terlihat pada :.

\section{Keletakan kompleks makam}

Secara umum kompleks makam biasanya terletak di atas sebuah bukit atau pada suatu tempat yang ditinggikan. Di sini terlihat bahwa kompleks makam Banyusumurup terletak di sebuah lembah yang dikelilingi oleh tiga gunung.

\section{Pembagian halaman}

Dalam suatu kompleks makam umumnya dijumpai pembagian halaman menjadi tiga atau lima bagian, dengan makam tokoh utama terletak pada halaman terakhir atau halaman yang paling belakang. Di kompleks makam Banyusumurup hanya terdapat pembagian halaman menjadi dua bagian, dan makam tokoh utama terletak dalam satu halaman bersama-sama dengan makam-makam lainnya.

3. Perlakuan terhadap tokoh yang dimakamkan.

Pada makam raja-raja dan kaum kerabatnya, dalam hal ini terutama menyangkut makam raja-raja Mataram Islam, biasanya waktu-waktu nyekar atau ziarah selalu dihadiri oleh kerabat kerajaan, dalam hal ini kerabat kraton Surakarta maupun Yogyakarta. Sedang kan di kompleks makam Banyusumurup yang merupakan makam kerabat kerajaan, upacara caos dahar hanya dilakukan oleh para juru kunci makam, dengan perlengkapan yang dikirim dari kraton Surakarta maupun Yogyakarta tanpa dihadiri oleh kerabat kraton.

Perbedaan-perbedaan tersebut di atas tampaknva disebabkan oleh st: tus tokoh-tokoh yang dimakamkan di sana semasa hidupnya. Tokoh-tokol tersebut meskipun merupakan kerabat kerajaan, juga dianggap berstatus sebagai pembangkang terhadap kekuasaan raja yang memerintah pada waktu itu, yaitu Sunan Mangkurat I. Meskipun demikian kompleks makam 
Banyusumurup masih terletak satu konteks dengan kompleks makam raja-raja Mataram Islam lainnya, yaitu di daerah Imogiri. Hal ini dapat disejajarkan dengan makam Kyai Ageng Mangir di Kota Gede, yaitu separuh makam terletak di dalam cungkub dan separuh lainnya terletak di luar cungkub. Jelas terlihat. bahwa status seseorang semasa hidupnya tercermin pula pada bangunan makamnya.

\section{CATATAN}

!. Pembacaan tulisan dilakukan oleh Sdr. Kusẹn, staf: pengajar pada jurusan Arkeologi Fakultas Sastra UGM.

2. Berdasarkan daftar nama tokoh yang dimakamkan di Banyusumurup yang diperoleh dari bupati juru kunci makam, ternyata dijumpai nama Pangeran Cakranegara pada makam 17. Sedangkan pada kenyataannya nama Cakranegara tertera pada makam 4. Mengenai nama Cakranegara itu sendiri tidak dijumpai dalam sumber sejarah, terutama yang berkaitan dengan periode sekitar abad 17 Masehi. Nama tokoh yang mendekati nama Cakranegara adalah Raden Cakra, putra Panembahan Krapyak (1601 - 1614) dari istri keduanya, yaitu Lung Ayu dari Ponorogo. Raden Cakra, atau yang dikenal juga sebagai Pangeran Selarong, dibunuh atas perintah Sunan Mangkurat I pada tahun 1668 dan dimakamkan di Banyusumurup (de Graaf, 1962:29).

3. Mengenai tulisan pada makam 6 belum dapat dikemukakan apakah tulisan itu merupakan sengkalan atau mempunyai makna lain.

K e p u s t a $k$ a a $n$

Graaf, H.J. de 1941

1962

Inajati Adrisijanti 1973
"Soerabaja in de XVII eeuw van Koninkrijk tot Regentschap", Djawa 3, Mei 1941. Diterjemahkan oleh Suwandi. Yogyakarta : Balai Penelitian Sejarah dan Budaya.

: "De Regering ; van Sunan Mangkurat I. Tegal Wangi, Vorst van Mataram", VKI deel 33. 's-Gravenhage : Martinus Nijhoff.

"Kekunaan Islam di Imogiri. Tinjauan terhadap Seni Bangun dan Seni Hiasnya". Tesis pada jurusan Arkeologi Fakultas Sastra dan Kebudayaan UGM. 
Lucas P. Koestoro 1984

Moquette, J.P. 1912

Olthoff, W.L.

1941

Serrurier, L. 1896
Laporan Ekskavasi Tahap IV Situs Bogang. Kacamatan Selomerto, Kabupaten Wonosobo. Jawa Tengah. Balai Arkeologi Yogyakarta. Tidak diterbitkan.

"De Grafsteenen te Pase en Griessee Vergeleken met Dergelijke Monumenten uit Hindoestan", TBG LIV, Batavia : Albracht \& Co., hlm. 208.214

Poenika Serat Babad Tanah Djawi Wiwit Saking Nabi Adam Doemoegi ing taoen 1647. 's-Gravenhage : Martinus Nijhoff.

De Wajang Poerwa. Leiden : E.J. Brill.
Uka Tjandrasasmita 1975
: "Art de Majopahit et Art du Pasisir", Archipel 9. Bandung : P.T. Karya Nusantara. hlm. 93 - 98.

\section{Lampiran}

Daftar nama tokoh yang dimakamkan di Banyusumurup

(disalin dari bupati juru kunci makam Banyusumurup)

Makam 1.: Kanjeng Gusti Pangeran Pekik

Makam 2 : Kanjeng Gusti Pangeran Lamongan

Makam 3 : Kanjeng Ratu Mangkurat (Rara Oyi)

Makam 4: Raden Ayu Cutang

Makam 5: Raden Ayu Kleting Wulung

Makam 6: Raden Ayu Jambul

Makam 7 : Putra Timur

Makam 8 : Pangeran Demang

Makam 9: Tidak diketahui

Makam 10 : Ratu Lembah

Makam 11 : Raden Kertanagoro

Makam 12： Raden Singolesono

Makam 13 : Raden Martopuro

Makam 14: Raden Kertonadi

Makam 15 : Raden Wongsokusumo

Makam 16: Pangeran Jogorogo

Makam 17: Raden Cokronagoro

Makam 18: Raden Joyomiruda

Makam 19: Raden Singorawa

Makam 20 : Raden Jonopuro 
Makam 21 : Raden tomo

Makam 22 : Raden Pawirotaruno

Makam 23 : Raden Senjoyo

Makam 24 : Raden Honggojoyo

Makam 25 s/d 30 : Tidak diketahui

Makam 31 : Raden Tondo

Makam 32 : Raden Lamongan

Makam 33 : Raden Mertopuro

Makam 34 : Raden Kariyonagoro

Makam 35 : Raden Wirokusumo

Makam 36 : Raden Irowongso

Makam 37 : Raden Wongsocitro

Makam 38 : Raden Wirosari

Makam $39 \mathrm{~s} / \mathrm{d} 49$ : Tidak diketahui

Makam 50 : Pangeran Bei Joyokusumo

Makam 51: Raden Aryo Kusumo

Makam 52 : Raden Atmojokusumo

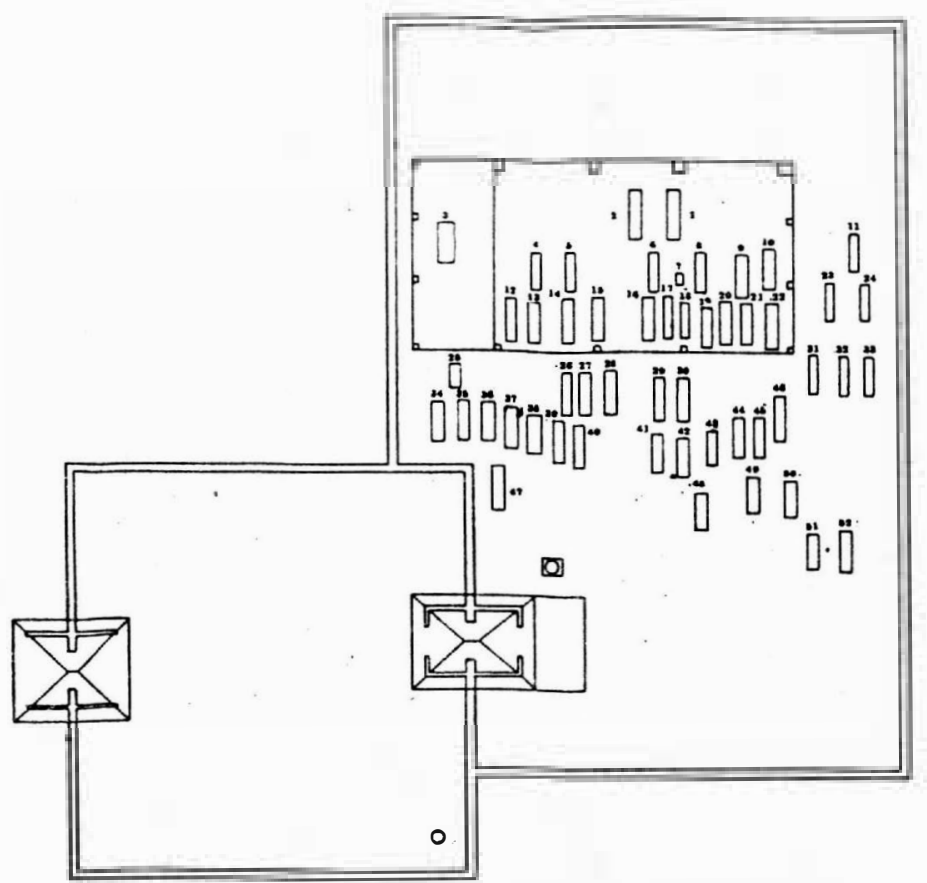

Denah Kompleks Makam Banyusumurup Imogiri (Skala: $1: 200$ ) 